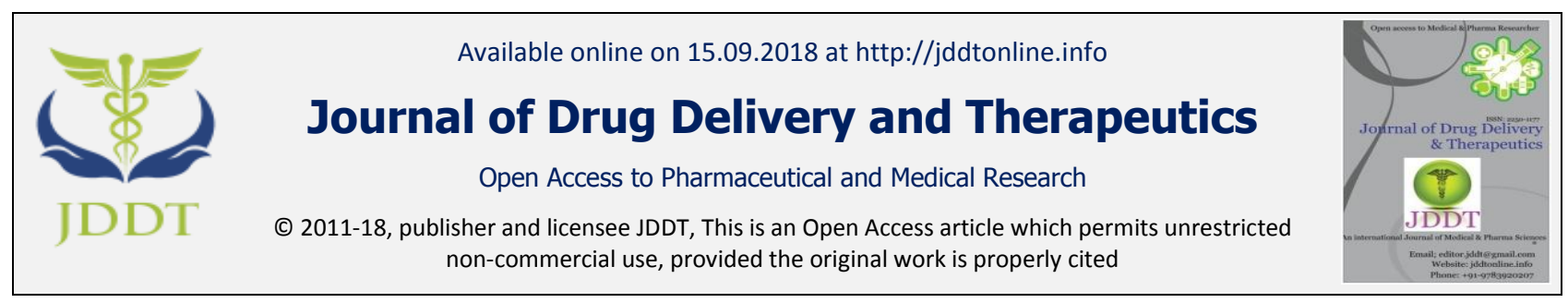

Open ${ }_{\text {Access }}$

Review Article

\title{
AN OVERVIEW ON PHARMACOVIGILANCE: A KEY FOR DRUG SAFETY AND MONITORING
}

\author{
Vipin Kesharwani*", Mohd. Asad Farooqui ${ }^{1}$, Nikhil Kushwaha ${ }^{1}$, Ravi Kesh Singh ${ }^{1}$, \\ Pankaj Kumar Jaiswal ${ }^{2}$
}

${ }^{1}$ Chandra Shekhar Singh College of Pharmacy, Koilaha, Puramufti, Kaushambi, Uttar Pradesh, India

${ }^{2}$ Department of Pharmaceutical Sciences, Dibrugarh University, Dibrugarh Assam, India

\begin{abstract}
Pharmacovigilance outlined by the globe Health Organization (WHO) because the science and series of activities about the detection, evaluation, understanding rejection of adverse impact or Associate in Nursing different drug connected problem' and a clinical test could be an analysis study in human volunteers to answer specific health queries. Fastidiously conducted clinical trials square measure quickest and safest thanks to realizing treatment that employment in individuals and thanks to improving health. Play a crucial role in guaranteeing that patient to be provided the safe drug. The Pharmacovigilance has been recognizing to play a crucial role in the rational use of the drug by providing data concerning the adverse impact possess by drug normally population. The information of drug Adverse Drug Reaction (ADRs) are often increased by numerous suggests that such information studies, intensive observation, spontaneous reportage and different new method at dictatorial and scientific level square measure being developed with the intention of step-up Pharmacovigilance. As a result of assessment strategies are not entirely void of individual judgments, integrator reliableness is often low. In conclusions, there's still no methodology universally accepted for casualty assessment of ADRs.
\end{abstract}

Keywords: Adverse Drug Reaction, Clinical test, Pharmacovigilance, Treatment.

Article Info: Received 02 Aug, 2018; Review Completed 09 Sep 2018; Accepted 10 Sep 2018; Available online 15 Sep 2018

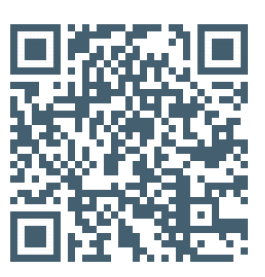

\section{Cite this article as:}

Kesharwani V, Farooqui MA, Kushwaha N, Singh RK, Jaiswal PK, An overview on pharmacovigilance: a key for drug safety and monitoring, Journal of Drug Delivery and Therapeutics. 2018; 8(5):130-135

DOI: http://dx.doi.org/10.22270/jddt.v8i5.1970

*Address for Correspondence:

Vipin Kesharwani, Katara Nagar, Manjhanpur, Kaushambi, Uttar Pradesh, India, Pin Coad- 212207

\section{INTRODUCTION}

According to the world Health Organization, "Pharmacovigilance is defined as the science and activities relating to the detection, assessment, understanding and prevention of adverse effect or any other possible drug-related drawback, particular, long term and short term adverse effects of medicines" 1 . The history routes of the word "Pharmacovigilance" are: Pharmakon (Greek word of 'drug') and vigilare (Latin word for 'to keep watch') ${ }^{2}$.

Pharmacovigilance is not new to Asian nation and has infect been going on from $1998{ }^{3}$.When Asian nations decided to join the Uppsala centre for adverse event monitoring. Spontaneous reporting of adverse drug reaction and adverse events is an important tool for gathering the safety data for early detection. it is widely accepted that a drug has to go through various phases of trial to establish its safety and efficacy before it is marketed commercially. However, the clinical trials offer various limitations, like; strict criteria of inclusion and exclusion make it to be used in a very selective group of patients; special population groups like kids, pregnant lady, and maturity population are not studied during the trials; and other factor causing drug reactions such as genetic factors, environmental factors, and drugdrug interactions may not have been studied during the clinical trials ${ }^{4}$. 
These adverse drug reaction (ADRs) not only increase the suffering of patients but also increase morbidity and mortality in conjunction with a financial burden on society. the overall incidence of ADRs in hospitalized patients is estimated to be $6.7 \%(0.1-0.85 \%)^{5}$. data indicates that in patients World Health Organization experience ADRs death rates area unit $19.18 \%$ higher and the length of hospital stay is $8.25 \%$ higher. The Total medical cost for patient with ADRs unit increased by average of $19.86 \%{ }^{6}$.

\section{METHOD OF CAUSALITY ASSESSMENT}

Many researchers developed numerous ways of relation assessment of ADRs by mistreatment totally different criteria like written record relationship between the administration of the drug and also the incidence of the ADR, screening for non drug connected causes, confirmation of the reaction by in vivo or vitro tests, and former data on similar events attributed to the suspect drug or to its therapeutic category, etc. to outline ADRs in several categories ${ }^{7}$. However as a result of there aren't any outlined diagnostic criteria or classes, interrater and intra-rater variability may be large ${ }^{\mathbf{8}}$. Currently, there's no universally accepted ways of accessing relation of ADRs ${ }^{[9]}$. We tend to describe here 3 broad classes of varied ways of relation assessment: professional judgement/global contemplation, algorithms and probabilistic ways (Bayesian approaches) ${ }^{9}$.

\section{HISTORY OF PHARMACOVIGILANCE IN ASIAN NATION}

Table 1: The sequential Pharmacovigilance developments with special reference to India

\begin{tabular}{|c|l|}
\hline Year & Developments \\
\hline 1747 & Very first known clinical trials by James Lind, proving the usefulness of lemon juice in preventing scurvy. \\
\hline 1937 & Death of more than 100 children due to toxicity of sulfanilamide. \\
\hline 1950 & Apalstic anemia reported due to Chloramphenicol toxicity. \\
\hline 1961 & Worldwide tragedy due to thalidomide toxicity \\
\hline 1963 & 16 th World Health congregation recognize significant to rapid action on Adverse Drug Reactions (ADRs). \\
\hline 1968 & WHO research project for international drug monitoring on pilot scale. \\
\hline 1996 & Global standards level clinical trials initiated in India. \\
\hline 1997 & India attached with WHO Adverse Drug Reaction Monitoring Program. \\
\hline 1998 & Initiation of Pharmacovigilance in India. \\
\hline 2002 & 67 th National Pharmacovigilance Center established in India. \\
\hline $2004-05$ & India launched National Pharmacovigilance Program. \\
\hline 2005 & Accomplishment of structured clinical trials in India. \\
\hline $2009-10$ & Pharmacovigilance Program (Pv. PI) started. \\
\hline
\end{tabular}

Pharmacovigilance in Asian nation started from 1986. A proper Adverse Drug Reaction (ADR) watching system was initiated with twelve regional centers, every covering a population of fifty million. However, no noteworthy growth was created. Later in 1997, Bharat joined the globe Health Organization (WHO) and Adverse Drug Reaction (ADR) scrutinized program primarily based at 2 urban centers, Kingdom of Sweden however got fail. Hence when 2005 UN agency supported and World Bank fund National Pharmacovigilance Programme (NPPV) of Bharat was created operational $\mathbf{2 , 1 0 , 1 1 , 1 2}$. The sequential Pharmacovigilance developments shown in below table no. $1^{1,13,14}$.

\section{AIM OF PHARMACOVIGILANCE}

Improvement of patient care and safety in respect to use of medicines with medical and paramedical interventions remains to be a crucial parameter. The main objectives of Pharmacovigilance involve exhibiting the effectuality of medicine by observation their adverse impact profile for several years from the research lab to the pharmacy; trailing any forceful impact of drug rising public health and safety respect to the utilization of medicines; encouraging the safe, rational and efficient use of drugs; promoting understanding, educations and clinical coaching in Pharmacovigilance; and effective communications to the generic public ${ }^{15}$.

\section{METHODS UTILIZED IN PHARMACO- VIGILANCE}

The activities undertaken in the name of Pharmacovigilance can be roughly divided into three groups: regulatory, industry, and academia. Regulatory Pharmacovigilance is driven by the aim to provide drugs with a positive benefit- harm profile to the public. Some of the problems related to regulatory post-marketing surveillance will be discussed in this context, followed by a description of the methods used to detect new ADRs and a discussion of the pros and cons of each method ${ }^{16}$.

- Dangaumou's French method ${ }^{\mathbf{1 7}}$

- Kramer et al. method ${ }^{\mathbf{1 8}}$

- Naranjo et al. methodology (Naranjo scale) ${ }^{19}$

- Balanced assessment method ${ }^{20}$

- Ciba-Geigy method ${ }^{\mathbf{2 1}}$

- $\quad$ Loupi et al. method ${ }^{22}$

- Roussel Uclaf casuality assessment method ${ }^{23}$

- Australian method ${ }^{24}$ 


\section{ADVERSE DRUG REACTION (ADRs)}

An adverse drug (ADRs) is outline as AN fortuitous and harmful to a health product that causes at the doses sometimes or tested for the diagnosing, hindrance or treatment of a malady or the alteration of AN organic function ${ }^{\mathbf{2 5 , 2 6 , 2 7}}$ Though, it's tough to acknowledge the actuating agent connected with the adverse drug reaction (ADRs) encountered contain quite ingredients ${ }^{28}$. The magnitude f risk must be thought-about together with magnitude of expected medical specialty advantages decide whether or to use a specific drug in an exceedingly given patient ${ }^{29}$. Adverse drug (ADRs) are classified in two ways-

- $\quad$ Foreseeable (Type-A) Reaction

- $\quad$ Unpredictable (Type-B) Reaction
Predictable (Type-A) Reaction: These square measure supported pharmacologic properties of the medicine like increased however quantitatively response to the drug that embody aspect effects, Gyanogenic effects and consequences of drug withdrawal ${ }^{\mathbf{2 8 , 3 1}}$.

Unpredictable (Type-B) Reaction: These square measure supported peculiarities of patient and not on drug's acknowledged actions; embody allergic reaction and specialty. These are less common, usually non dose connected, typically a lot of serious and need withdrawal of drug. an inventory of some suspected and acknowledged medicine related to adverse effect ${ }^{28,30,31}$. The known Drug and its adverse effect shown in below table no. $2^{32}$.

Table 2: known Drug and its adverse effect.

\begin{tabular}{|l|l|}
\hline Drug & Adverse Drug Reactions (ADRs) \\
\hline Thalidomide & Phocomelia, Multiple defects \\
\hline Methotraxate & Multiple defects, Foetal death \\
\hline Androgen & Virilization, limb, esophageal, cardiac defects \\
\hline Progestins & Virilization of female foetus \\
\hline Stilboestrol & Vaginal carcinoma in teenage female offspring \\
\hline Tetracyclines & Discolored or deformed teeth, retarded bone growth \\
\hline Warfarin & nose, eye and hand defects, growth retardation \\
\hline Phenytoin & Various malformations \\
\hline Lithium & Foetal goiter, cardiac and other abnormalities \\
\hline Aspirin/ Indomethacin & Premature closer of ductus arteriosus \\
\hline
\end{tabular}

\section{SIGNAL DETECTION AND EVALUATION STEPS:}

The evaluation steps for safety and prevention of ADR are shows in figure no. 1. (Reproduced with permission from the Report of CIOMS Working Group VIII C 29[CIOMS-2010].

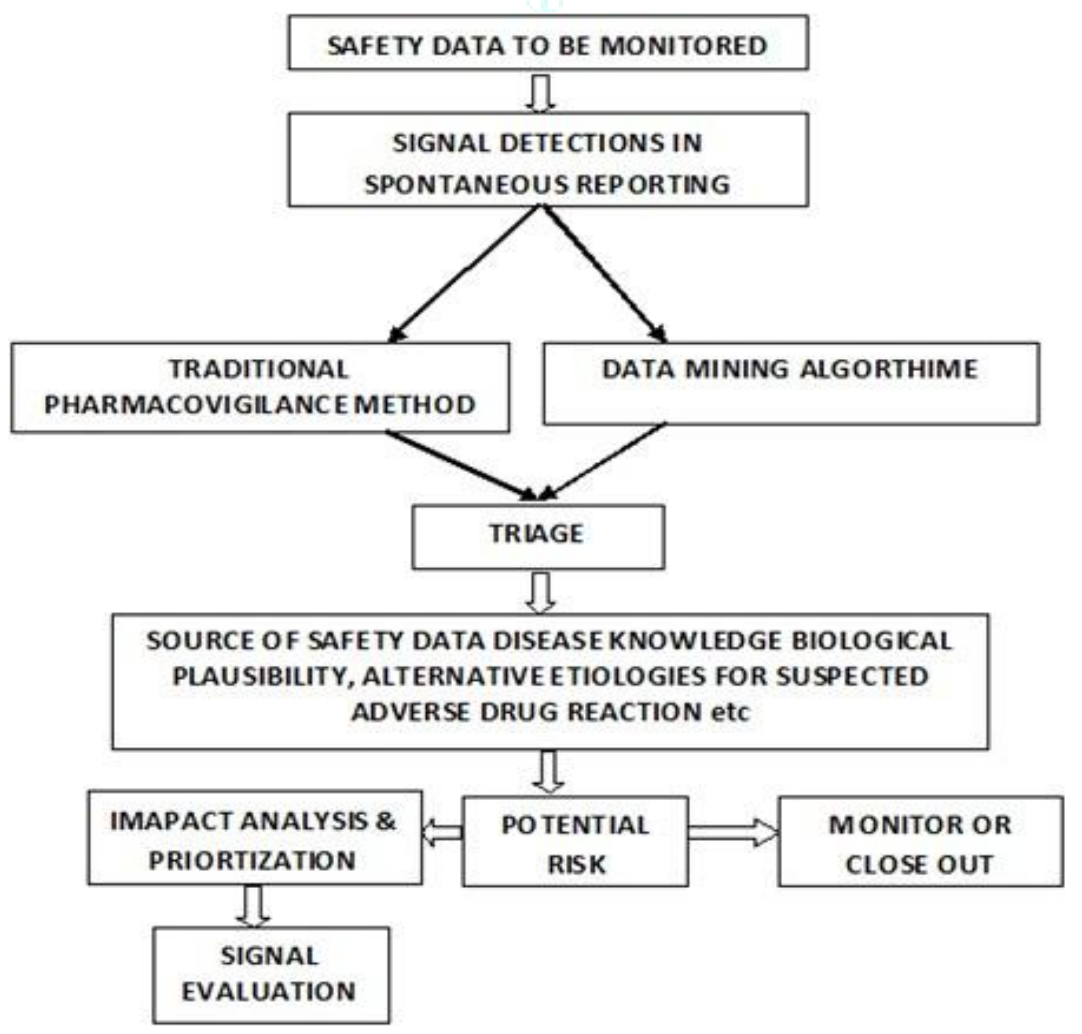

Figure 1: Signal detection and evaluation steps (reproduced with permission from the Report of CIOMS Working Group VIII ${ }^{33}$ () CIOMS 


\section{CLINICAL TRIAL}

A clinical trial could be an analysis study that tests a replacement medical treatment or a replacement manner of mistreatment Associate in Nursing existing treatment to ascertain if it'll be higher thanks to stop and screen for diagnose or treat disease ${ }^{34}$. Wide selection of dose of the study drug is given to Associate in Nursingimals subjects or to an in-vitro substrate so as to get preliminary effectuality, toxicity and pharmacokinetic information ${ }^{35}$. The phase of clinical trial study was shown in figure no. 2.

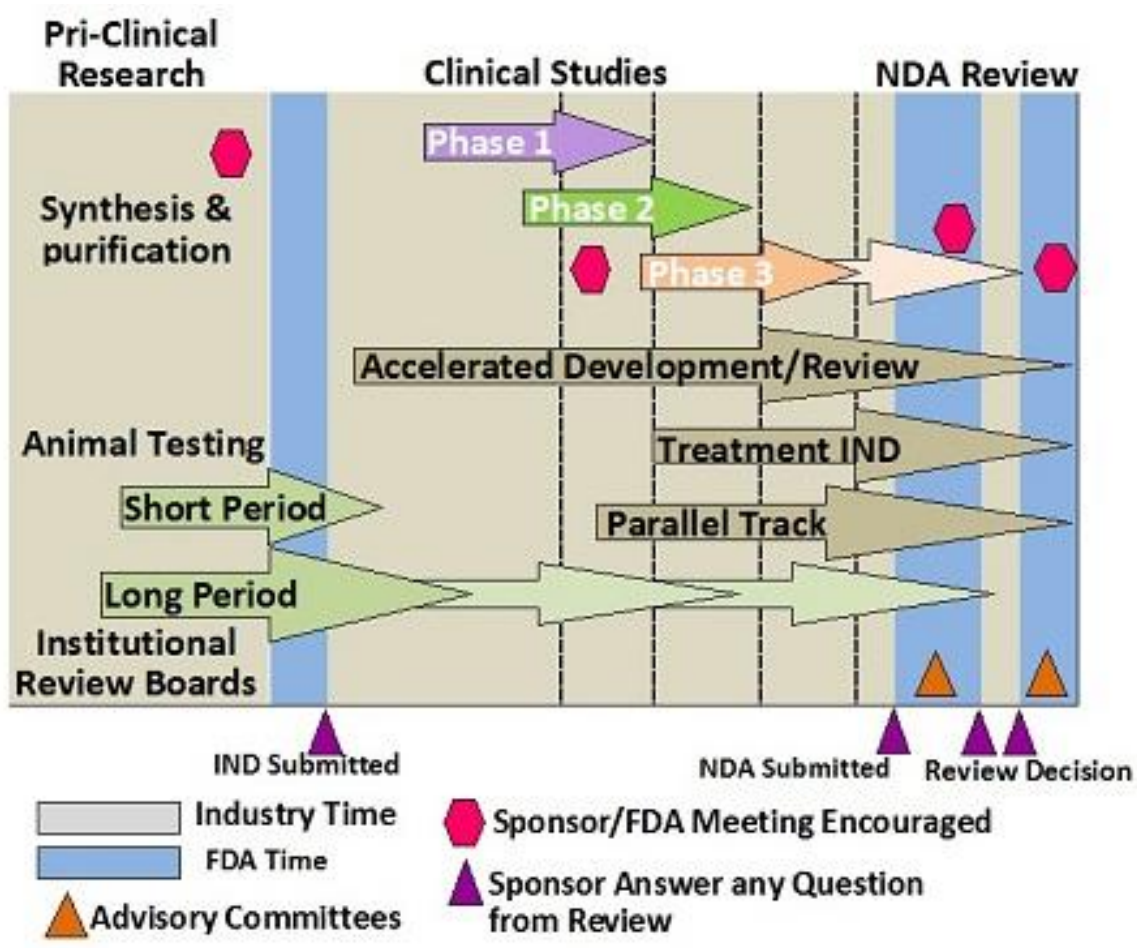

Figure 2: Phase of Clinical Trial

Before pharmaceutical firms begin clinical test on a drug they conduct in depth pre-clinical studies ${ }^{\mathbf{3 6}}$.

\section{Pre-Clinical Studies}

Pre-clinical studies involve in vitro (i.e. tube or laboratory) studies and trial or animal population. Wide travel dose of the study in drug area unit given so as to get preliminary effectualness, toxicity and pharmacokinetic data and to help pharmaceutical firms decide whether or not it's worthy to travel ahead with more testing.

\section{Clinical Studies}

\section{Phase-0}

Phase zero may be a recent designation for exploratory, first-in-human trial conducted in accordance with U.S. food and Drug administration (FDA) 2006 steerage on exploratory. Distinctive options of part zero trials embrace the administration of single sub-therapeutics doses of the study drug to a little range of subjects (1015) to collect preliminary information on the agent's pharmacological medicine (how to body processes the drug) and Pharmacodynamics (how the drug add the body).

\section{Phase-I}

Phase I path area unit 1st stage of testing in human subject. Ordinarily a little (20-80) cluster of healthy volunteers are going to be elite. This part includes trails designed to assess the security (Pharmacovigilance) tolerability, pharmacological medicine and Pharmacodynamics of a drug.

There are unit totally different styles of clinical trial trials.

- SAD: Single Ascending Dose studies area unit those within which tiny cluster of subjects' area unit given one dose of the drug whereas they're ascertained and tested for a amount of your time.

- MAD: Multiple Ascending Dose studies area unit conducted to raise perceive the pharmacological medicine of multiple dose of drug.

\section{Phase-II}

Once the initial safety of the study drug has been confirmed in clinical trial trials, clinical trial trials area unit performed on giant cluster (20-300) and area unit designed to assess however well the drug work in addition on continue clinical trial safety assessment in a very larger cluster of volunteers and patients. clinical trial studies area unit generally divided into clinical trial A and clinical trial B. clinical trial A is specifically style to access dosing necessities ( what proportion drug ought to be given), wherever as clinical trial $\mathrm{B}$ is specifically designed to check effectualness ( however well the drug work the prescribed dose (s)). Some trials mix clinical trial and clinical trial, and take a look at each effectualness and toxicity. 


\section{Phase-III}

Phase III studies irregular controlled multi-center trials on giant patients cluster (300-3,000 or additional relying upon the disease/ medical condition studied) and area unit geared toward being the definitive assessment of however effective the drug is compared with current 'gold standard' treatment.

\section{Phase-IV}

Phase IV trial is additionally called Post promoting police work Trial. Phase IV trials involves the security police work (Pharmacovigilance) and current technical support of a drug once it receive permission to sold.

Table 3: Phases of Clinical Trial

\begin{tabular}{|l|l|}
\hline Phase & Group \\
\hline 0 & $10-15$ \\
\hline 1 & $22-80$ \\
\hline A & Single Ascending Dose (SAD). \\
\hline B & Multiple Ascending Dose (MAD) \\
\hline 2 & $20-300$ \\
\hline 3 & $300-3000$ \\
\hline 4 & Post Marketing Surveillance Trial. \\
\hline
\end{tabular}

The security police work is intended to observe any rare or semi permanent adverse result over a far larger

\section{REFERENCES}

1. World Health Organization. The importance of pharmacovigilance - safety monitoring of medicinal products. World Health Organization, Geneva.2002;

2. Shuka SS, Gidwani B, Pandey R, Rao SP, Singh V, Vyas A, Importance pharmacovigilance in Indian Pharmaceutical Industry, Asian Journal of Research in Pharmaceutical Science 2012; (2): 04-08.

3. WHO, Pharmacovigilance, ensuring the safe use of medicines, Geneva WHO.2004;

4. Mann RD, Andrews EB,eds. John Wiley \& Sons Ltd, Pharmacovigilance, Chichester. 2002.

5. Lazarou J, Pomeranz BH, Corey PN, Incidence of adverse drug reactions in hospitalized patients, JAMA, 1998; 279:1200-1205.

6. Bord CA, Rachl CL, Adverse drug reactions in United States hospitals. Pharmacotherapy, 2006; 26(5):601-08.

7. Danan G, Benichou C, Causality assessment of adverse reactions to drugs- a novel method based on the conclusions of international consensus meetings: application to druginduced liver injuries, J ClinEpidemiol, 1993; 46(1):132142.

8. Blanc S, Leuenberger P, Berger JP, Brooke EM, .Schelling $\mathrm{JL}$, Judgments of trained observers on adverse drug reactions, ClinPharmacol Ther 1999; (25):493-498.

9. Taofikat BA, Savovi J, Ernst E, Methods for Causality Assessment of Adverse Drug Reactions A Systematic Review, Drug Safety, 2008; 31(1):21-37.

10. Jadhav S, Chakraborthy G, Pharmacovigilance in India Need of Hour, Journal of Advances in Pharmacy and Healthcare Research (JAPHR) 2011; 101-03.

11. Amarnath S, Jaikumar S, Basalingappa S, Thulasimani M, Ramaswamy S, Pharmacovigilance for Health Care Professional Students, Research Journal of Pharmaceutical, Biological and Chemical Sciences (RJPBCS)4 JanuaryMarch 2013; 1204-1217.

12. Muraraiah S, Rajarathna K, Sreedhar D, Basavalingu D, Jayanthi C.R, A questionnaire study to assess the knowledge, attitude and practice of Pharmacovigilance in a paediatric patient population and longer period than was potential throughout the harmful result discovered by phase IV trials might end in a drug being not sold, or restricted to bound uses. Recent example involves Baycol (branch names Bycol and lipobay) trogelitazone (Rezulin and Vioxx-vioxx) ${ }^{35}$. The segment of phase IV was shown in figure no. 3 .

\section{CONCLUSION}

In conclusion there is still no method universally accepted for casuality assessment of ADRs. Pharmacovigliance study of the science and series of activities relating to the detection, evaluation, understanding and avoidance of Adverse Effect or any other drug related problem. The knowledge of drugs Adverse Drug Reaction (ADRs) can be augmented by various mean such database studies, intensive monitoring, spontaneous reporting.

\section{ACKNOWLEDGEMENT}

I am indeed obliged and sincerely thankful to H.O.D. of Chandra Shekhar Singh College of Pharmacy Mr. Dilip Kr. Patel, Miss Ruby Tabassum for his generous help and special thank to my senior Mr. Pankaj Kumar Jaiswal and my class friends for the help nd support.

tertiary care centre, Journal of Chemical and Pharmaceutical Research, 2011; 416-422.

13. Ghosh R, Bhatia M.S, Bhattacharya S.K, Pharmacovigilance: Master Key to Drug Safety Monitoring and its Status in India: Delhi Psychiatry Journal, 15 October 2012; 412-415.

14. Kulkarni M.D., Baig M.S, Chandaliya K.C, Doifode S.M, Razvi S.U, Sidhu N.S, Knowledge Attitude and Practice of Pharmacovigilance among Prescribers of Government Medical College and Hospital, Aurangabad (Maharashtra), International Journal of Pharmacology and Therapeutics, 2013; 3:10-18.

15. WHO, Pharmacovigilance: ensuring the safe use of medicines, Geneva: WHO.2004;

16. Zarin DA, Young JL, West JC, Challenges to evidence based medicine: a comparison of patients and treatments in randomized controlled trials with patients and treatments in a practice research network. Soc Psychiatry Psychiatr Epidemiol, 2005; 4027-35.

17. Dangoumau J, Evreux JC, Jouglard J, Mehtod for determination of undesirable effects of drugs, Therapie, 1978; 33(3):373-81.

18. Kramer MS, Leventhal JM, Hutchinson TA, Feinstein AR, An algorithm for the operational assessment of adverse drug reactions: I. Background, description, and instructions for use. JAMA, 1979; 242(7):623-32.

19. Naranjo CA, Busto U, Sellers EM, Sandor P, Ruiz I, Roberts EA, A method for estimating the probability of adverse drug reactions.ClinPharmacolTher1981; 30(2):239-45.

20. Lagier G, Vincens $M$, Castot A, Imputability in drug monitoring: Principles of the balanced drug reaction assessment method and principal errors to avoid. Therapie, 1983; 38(3):303-18.

21. Venulet J, Ciucci A, Berneker GC, Standardized assessment of drug-adverse reaction associations - Rationale and experience. Int J ClinPharmacolTherToxico, 1980; 18(9):381-8.

22. Loupi E, Ponchon AC, Ventre JJ, Evreux JC, Imputability of a teratogenic effect. Therapie, 1986;41(3):207-10. 
23. Danan G, Benichou C, Causality assessment of adverse reactions to drugs--I. A novel method based on the conclusions of international consensus meetings: Application to drug-induced liver injuries, J ClinEpidemiol, 1993; 46(11):1323-30.

24. Mashford ML, The Australian method of drug-event assessment: Special workshop - regulatory. Drug Inf J, 1984; 18(3-4):271-273.

25. Bhosale U, Jaiswal S, Yegnanarayan R, Godbole G, A Pharmacovigilance Study of Anti- Asthmatic Agents in Patients of Bronchial Asthma at a Tertiary Care Hospital, Journal of Clinical \& Experimental Research,1May-August 2013; 26-30

26. Sharma S, Phadnis P, Gajbhiye S, Pharmacovigilance: Its Awareness and Impact Care Teaching Medical College in Central India Impact- Study in a Tertiary care Teaching Medical College in Central India, International Journal of Pharmaceutical Research and Bio- Science (IJPRBS), 2013; 2:234-247.

27. Padmavathi GV, Beere N, Divakara P, Suresh KP, Surendranath A, Patel RS, Screenplay of pharmacovigilance among nursing staff in Bangalore,2 February 2013; 365-370.

28. Maiti B, Nagori B.P., Singh R, Kumar P, Upadhyay N, Recent Trends in Herbal Drugs: A Review, International Journal of Drug Research and Technology, 2011; 117-25.
29. Chakraverty R, Banerjee A, Emerging Issues in Pharmacovigilance of Herbal Medicines in India: International Journal of Pharmaceutical Sciences Review and Research, 20 May -Jun 2013; 40-42.

30. Rama P, Prudence AR, Georgy A, Pharmaovigilance: Perspectives and Future Challenges in Indian Scenario, Asian Journal of Pharmaceutical and Clinical Research, 2011; 4:0104.

31. Rohilla A, Kumar V, Sharma KM, Dahiya A, Kushnoor A, Pharmacovigilance: Needs and Objectives, Journal of Advanced Pharmacy Education \& Research, 2 Oct-Dec 2012; 201-205.

32. Leon L, Herbert A. Liberman, Joseph L. Kanig, Varghese Publishing House, Hind Rajasthan Building Dadar, Mumbai, 3rdEdition, 239-240.

33. CIOMS Working Group VIII. Practical aspects of signal detection in pharmacovigilance. Council for International Organizations of Medical Sciences (CIOMS), Geneva.2 010.

34. Information about clinical trial. Available from :URLhttp://www.temple.edu/pascope/about-trials.html

35. Clinical trial wikipedia, the free encyclopedia: Available from, URLhttp://en.wikipedia.org/ wiki/clinical_trial Jan 28 2008;

36. Kulkarni SK, Hand Book of Experimental Pharmacology, 3rd ed. Vallabh Prakashan New Delhi, 2004; P21. 